\title{
Are native bees and Apis mellifera equally efficient pollinators of the rupestrian grassland daisy Aspilia jolyana (Asteraceae)?
}

\author{
Pietro K. Maruyama ${ }^{1,2 *}$ (D), Carlos E. P. Nunes ${ }^{1}$ (D), Jeferson Vizentin-Bugoni ${ }^{3}$ (i), Simone Gustafsson ${ }^{4}$ (]) \\ and Leonor Patricia Cerdeira Morellato ${ }^{5}$ (1)
}

Received: April 12, 2018

Accepted: May 9, 2018

\begin{abstract}
Most angiosperms rely on animals for pollination, and insects, especially bees, are the most frequent pollinators. Many native Neotropical plants are frequently visited by the invasive honeybee (Apis mellifera), but its role in the pollination of these plants has been little investigated. We assessed the contribution of various floral visitors, including native bees and the honeybee, on the pollination of a generalist rupestrian grassland daisy, Aspilia jolyana (Asteraceae), in Serra do Cipó, Espinhaço Mountain Range, Brazil. We recorded floral visitors and measured the seed set resulting from one single visitation. We observed a total of 442 visits, mostly by bees, with Bombus pauloensis and Apis mellifera being the most common floral visitors. Other visitors included many other species of bees, flies, hummingbirds, wasps and butterflies. Pollinators significantly increased seed set in comparison to non-visited (bagged) capitula. Moreover, there was no difference among bee species/groups in their contribution to seed set. Thus, A. jolyana benefits from its generalized pollination strategy, and frequent bee visitors, including several native species and the invasive honeybee, are equally effective pollinators for this generalist daisy of rupestrian grasslands.
\end{abstract}

Keywords: bee pollination, Bombus pauloensis, generalization, honeybee, invasive species, pollination efficacy, Serra do Cipó

\section{Introduction}

Generalization in interactions with pollinators may ensure plant reproduction in face of spatio-temporal variation in the availability of floral visitors (Waser et al. 1996; Brito et al. 2017). In fact, many flowers are visited by a range of species and functional groups of animals, thus are both ecologically and functionally generalists (Ollerton et al. 2007). Such generalist species are regarded as the main contributors to the dynamics and stability of the interaction networks between plants and floral visitors/ pollinators (Martín González et al. 2010). However, not all floral visitors are true pollinators and there may be considerable variation in the efficacy of different species comprising the pollinator fauna of a particular plant (e.g. Fumero-Cabán \& Meléndez-Ackerman 2007). Because of this, the perceived level of generalization in plant-pollinator interaction is likely overestimated, and when the efficacy of each pollinator is taken in account, higher specialization is often reported (King et al. 2013).

To assess the importance of distinct floral visitors as pollinators for a given plant, one can experimentally

\footnotetext{
1 Departamento de Biologia Vegetal, Instituto de Biologia, Universidade Estadual de Campinas, 13083-970, Campinas, SP, Brazil

2 Instituto de Biologia, Universidade Federal de Uberlândia, 38405302, Uberlândia, MG, Brazil

3 Natural Resources and Environmental Sciences Department, University of Illinois at Champaign-Urbana, 61820, Urbana, IL, USA

4 Center for Macroecology, Evolution and Climate, Natural History Museum of Denmark, University of Copenhagen, 2100, Copenhagen, Denmark

5 Laboratório de Fenologia, Departamento de Botânica, Instituto de Biociências, Universidade Estadual Paulista, 13506-900, Rio Claro, SP, Brazil
}

* Corresponding author: pietrokiyoshi@gmail.com 
control the exposition of flowers to specific visitors, and then assess their efficacy as pollinators by recording the number of pollen grains deposited on stigmas or fruit/seed set resulting from each single visit (e.g. Freitas \& Paxton 1998; King et al. 2013). The inclusion of efficacy measures shows that plant-pollinator interactions exhibit some consistent trend for specialization (Rosas-Guerrero et al. 2014; but see Ollerton et al. 2015), in which pollinator functional groups are most effective pollinators to plants showing a given set of floral traits - or syndromes (Fenster et al. 2004; King et al. 2013; Rosas-Guerrero et al. 2014). Yet, it is possible that even within a functional group of pollinators, for instance bees, there are differences on pollinator efficacy related to specific life-history traits such as sociality and behavior while visiting the flowers (Westerkamp 1991).

In this context, the invasive honeybee, Apis mellifera is often regarded as an ineffective pollinator despite its overwhelming abundance (Hung et al. 2018). For instance, A. mellifera can collect nectar while avoiding contact with pollen and may even remove pollen grains from stigmas (Westerkamp 1991; Gross \& Mackay 1998; Vicens \& Bosch 2000). Furthermore, because of its high abundance, it can suppress the activity of native bees through exploitative competition (Dupont et al. 2004; Thomson 2004). Nevertheless, A. mellifera can still provide sufficient pollination for plants (e.g., Freitas \& Paxton 1998; Fumero-Cabán \& Meléndez-Ackerman 2007), and there has been a great interest in contrasting the effectiveness of the honeybee with that of other indigenous floral visitors (e.g. Freitas \& Paxton 1998; Vicens \& Bosch 2000; Rader et al. 2009; Hung et al. 2018). Finally, assessing the role of invasive and dominant floral visitors such as $A$. mellifera in plant reproduction can benefit conservation planning and management strategies (e.g. Gross \& Mackay 1998).

Here, we characterize the pollinator fauna of the daisy Aspilia jolyana (Asteraceae) from the Brazilian mountain rupestrian grasslands, a megadiverse and threatened habitat (Silveira et al. 2016). Previous studies found this species to be a hub (generalist species connected to many others) in the network of plants and pollinators during the peak flowering period in rupestrian grasslands community (Carstensen et al. 2014; 2016). While recording the floral visitors, we experimentally quantified the efficacy of the most common bee visitors in facilitating pollination by quantifying the seed set, i.e., conversion of flowers to achenes, after controlled single visitation experiments (sensu Freitas 2013). We were interested in the role of different floral visitors as pollinators for this plant. Moreover, the role of the invasive honeybee in pollination is rarely assessed with experiments (Hung et al. 2018), even though A. mellifera is often a dominant floral visitor in diverse Neotropical communities (Souza et al. 2018). Thus, we asked whether invasive Apis mellifera and native bees have different effectiveness as pollinators of a generalist native plant.

\section{Materials and methods}

\section{Study site and species}

The study was conducted in October and November of 2016, in Serra do Cipó, which is located at the south of the Espinhaço Mountain Range, state of Minas Gerais, SE Brazil. We collected our data in the same locations previously sampled by Carstensen et al. (2014; 2016). The vegetation in the studied area, at ca. 1000 1200 m a.s.l., is campo rupestre or rupestrian grasslands, a species rich mountain vegetation characterized by small herbs and shrubs associated with rocky outcrops (Silveira et al. 2016; Morellato \& Silveira 2018).

Asteraceae is the most species rich plant family in the rupestrian grasslands (Silveira et al. 2016; Mota et al. 2018) and the studied species, Aspilia jolyana G.M.Barroso (Asteraceae) is one of the most abundant non-grass plant species in the area, especially at elevations around 1200 $\mathrm{m}$ a.s.l (Mota et al. 2018). Flowers of A. jolyana form a capitulum of $10.5 \pm 1.1 \mathrm{~mm}$ in length and $5.6 \pm 0.7 \mathrm{~mm}$ in diameter ( $\mathrm{n}=18$ capitula), with each floret having a tube of $5.7 \pm 1.2 \mathrm{~mm}$ ( $\mathrm{n}=20$ florets from 10 capitula) and providing $1.2 \pm 0.3 \mu$ of nectar with $27.6 \pm 6.4 \%$ of sugar concentration ( $\mathrm{n}=12$ florets from 7 capitula). In each capitulum, we counted $24.4 \pm 4.9$ florets ( $n=76$ capitula). The florets are protandrous, with initial pollen release by anthers. After one day, there is emergence and opening of the bifid stigma from the floral tube with elongation of the style. New stigmas emerge within the same capitulum for approximately one week.

\section{Floral visitors and single visitation experiment}

In total, we conducted 102 hours of focal plant observation in A. jolyana, from 08:00 to 16:00. We recorded all visitors, their number of visits, and we captured the insects for posterior identification whenever possible. To assess the efficacy of floral visitors as pollinators, we selectively exposed previously bagged capitula (i.e. bagged before anthesis of any floret) to distinct visitor species/ groups. We refer to efficacy as the per visit effect of floral visitors in seed set, and effectiveness when combining efficacy with the visitation frequency to express the overall importance of each pollinator species/groups (sensu Freitas 2013). Before any visit, we counted the number of exposed stigmas, as indicative of female phase flowers, and after the visitation we bagged the capitulum again. We later collected the bagged capitula, after the senescence of all florets and counted the number of mature achenes (Fig. S1 in supplementary material, $n=76$ ). The proportion of female flowers (stigmas) open at the moment of visit converted into achenes was taken as the measure of pollinator efficacy. Control treatments of bagged flowers not exposed to visitors revealed that this plant is able to spontaneously self-pollinate ( $n=56$, see Results). Hence, in some instances 
more achenes were formed than the number of stigmas open at the moment of the visit (in $19.7 \%$ of the samples). We set an upper limit of $100 \%$ for the rate of conversion to achene in such cases, as spontaneous self-pollination had in general low rate of flower to achene conversion (see Results). Our approach is based on the comparison of the relative contribution of different visitors, as there is no a priori reason to believe that self-pollination rates are different among distinct floral visitors. We reasoned that our response variable indicates the increment in seed set per capitulum when there is visitation, in contrast to spontaneous seed set. We also marked flowers exposed to free visitation and counted the total number of exposed stigmas in the capitulum and later the number of achenes as controls $(n=91)$ besides the permanently bagged flowers.

\section{Data analysis}

First, we compared the proportion of female flowers converted into achenes between the capitula from three different categories: (1) open visitation; (2) isolated from visitors and (3) all the single visitation flowers. To do so, we ran a Generalized Linear Model (GLM) with binomial distribution for proportion data, with seed set as the response variable and the exposition category as the predictor (Zuur et al. 2009). After detecting overdispersion, we re-ran the analysis assuming a quasi-binomial distribution (Zuur et al. 2009). Model residuals were checked for model validation. After finding a significant difference among categories, we ran a post-hoc Tukey test.

Second, we compared the specific efficacy among three species and two functional groups of the most frequent bee pollinators: Bombus pauloensis, Apis mellifera, small bees, Megachilidae bees and Melipona quinquefasciata. Together these bees performed $87.8 \%$ of the total visits and $89.5 \%$ of the single visitation trials (see Tab. 1). For this, we ran a second GLM with binomial distribution, with seed set as response variable and the bee pollinator as predictor (Zuur et al. 2009). We checked for overdispersion and distribution of the residuals to validate the model (Zuur et al. 2009). All analyses were conducted in R (R Core Team 2016).

\section{Results}

In total, we recorded 442 visits by 31 species (or morphospecies) of floral visitors in A. jolyana. Bees were more frequent visitors than other groups (Tab. 1; Fig. 1). Nevertheless, butterflies, flies, wasps and hummingbirds were recorded visiting the flowers legitimately. Exposition to floral visitors significantly affected seed set $(\chi 2=49.5$, $\mathrm{P}<0.001$; post hoc Tukey test between all categories $P<0.01$; Fig. 2A). Seed set was higher in open capitula $(24.4 \pm 8.5 \%$ of florets turned into achene per capitulum) than in bagged capitula (12.1 $\pm 9.3 \%$ ), with capitula exposed to only one visit setting an intermediary number of seeds
(17.6 $\pm 12.0 \%)$. When comparing the most frequent bee pollinators, however, no significant difference on pollination efficacy was observed between native bees or in relation to invasive Apis melifera $(\chi 2=1.9, \mathrm{P}=0.75$; Fig. $2 \mathrm{~B})$.

\section{Discussion}

Aspilia jolyana is indeed a generalist plant species, as indicated by a previous study that recorded 117 visits by 30 pollinator species to this plant in 252 hours of community-wide observations (Carstensen et al. 2014). Notably, our species-specific study only slightly increased

Table 1. List and functional group of floral visitors recorded in Aspilia jolyana (Asteraceae) at the Serra do Cipó, Brazil. The number of capitula samples for single visitation experiment is also shown. For the comparison among bee groups (Fig 2B), small bees (marked with ${ }^{*}$ ) and Megachilidade bees (marked with $\dagger$ ) were grouped together.

\begin{tabular}{|c|c|c|}
\hline Fuctional groups / Floral visitors & $\begin{array}{l}\text { Number of } \\
\text { visits }\end{array}$ & $\begin{array}{l}\text { Single visitation } \\
\text { samples }\end{array}$ \\
\hline \multicolumn{3}{|l|}{ Bees } \\
\hline Bombus pauloensis & 190 & 17 \\
\hline Apis mellifera & 106 & 21 \\
\hline Megachile sp. $\dagger$ & 31 & 5 \\
\hline Dialictus sp.* & 21 & 8 \\
\hline Melipona quinquefasciata & 11 & 4 \\
\hline Pseudagapostemon ochromerus* & 8 & 3 \\
\hline Augochloropsis sp.1* & 7 & 5 \\
\hline Ceratina sp.* & 6 & 2 \\
\hline Dichranthidium sp.1† & 6 & 2 \\
\hline Tetrapedia sp. & 6 & \\
\hline Megachile iheringi & 4 & \\
\hline Trigona spinipes & 3 & \\
\hline Augochloropsis sp.2* & 2 & 1 \\
\hline Centris tarsata & 2 & \\
\hline Centris sp. & 1 & \\
\hline Centris spilopoda & 1 & \\
\hline Megachilidae sp. & 1 & \\
\hline \multicolumn{3}{|l|}{ Flies } \\
\hline Toxomerus sp. & 7 & 3 \\
\hline Syrphidae sp.1 & 1 & \\
\hline Syrphidae sp.2 & 1 & \\
\hline Muscidae sp. & 1 & 1 \\
\hline \multicolumn{3}{|l|}{ Hummingbirds } \\
\hline Heliactin bilophus & 3 & \\
\hline Chlorostilbon lucidus & 1 & \\
\hline Colibri serrirostris & 1 & 1 \\
\hline \multicolumn{3}{|l|}{ Wasps } \\
\hline Braconidae sp.1 & 2 & 1 \\
\hline Braconidae sp.2 & 1 & 1 \\
\hline Scoila sp1. & 1 & \\
\hline Scoila sp2. & 6 & \\
\hline \multicolumn{3}{|l|}{ Others } \\
\hline Hymenoptera sp. & 1 & 1 \\
\hline Lepidoptera sp.1 & 1 & \\
\hline Lepidoptera sp.2 & 9 & \\
\hline
\end{tabular}



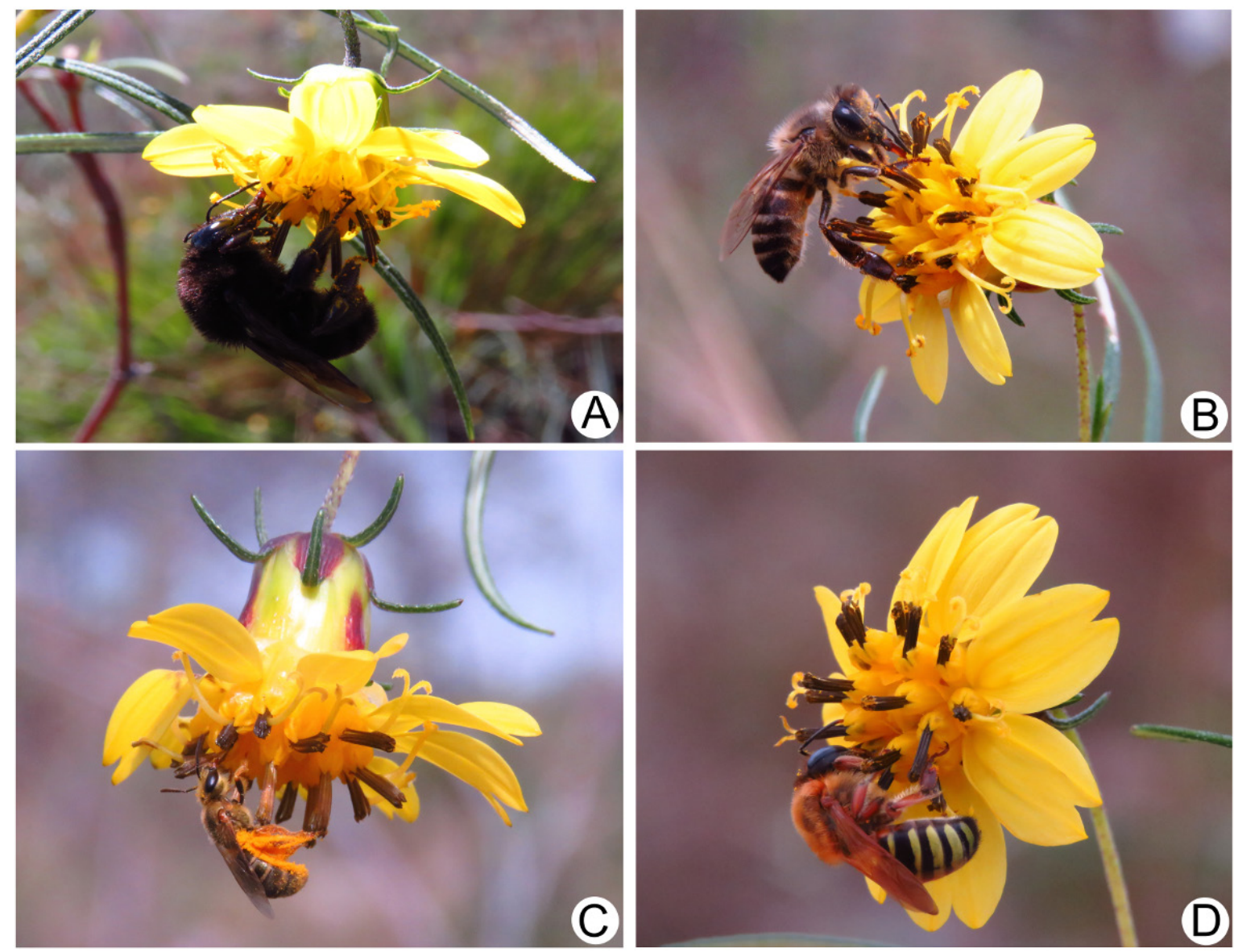

Figure 1. Some of the most frequent bee pollinators of Aspilia jolyana. A. Bombus pauloensis; B. Apis mellifera; C. Pseudoagapostemon ochromerus; D. Melipona quinquefasciata. Photos by J. Vizentin-Bugoni.

the richness of pollinators to 31 species, performing 442 visits. However, only a conservative estimate of $29.0 \%$ species/morphospecies $(\mathrm{n}=9)$ found here were also recorded by Carstensen et al. (2014). This suggests that potential pollinators associated to Aspilia jolyana are more diverse than reported by both studies.

The most frequent visitor of A. jolyana, Bombus pauloensis, seems to be the most consistent pollinator of this generalist plant in the study area (Carstensen et al. 2016). This consistent interaction illustrates a link between two of the most generalist species in the community (Carstensen et al. 2014; 2016), which potentially has a key role in the entire plant-pollinator network. Besides the dominance of bees as visitors of A. jolyana, we also confirmed visits by other insect groups such as butterflies, wasps, flies and beetles (Carstensen et al. 2014). Nonetheless, we recorded legitimate visits by three species of hummingbirds not recorded before (see Tab. 1), indicating that $A$. jolyana is even more generalist than previously regarded. This reinforces the assertion that hummingbirds from open habitats in the Cerrado domain are rather generalist in their floral nectar use (Maruyama et al. 2013).

Pollinator visits significantly increased the seed set in $A$. jolyana although this plant can pollinate itself spontaneously.
Likely, many visits are necessary during the life span of capitula for successful reproduction since florets mature sequentially. The difference on seed set between open and single visitation capitula also suggests that many visits are required for this plant to achieve maximum reproductive output. Thus, long-term viability of $A$. jolyana populations likely requires biotic pollination, although reproduction is assured in absence of pollinators. In this context, we showed that the most frequent bee species were equally effective in providing pollination. This also included the invasive honeybee, able to provide consistent pollination service by showing similar efficacy to native pollinators and ranked as the second most frequent visitor. Hence, at least in a generalist and morphologically non-restrictive flowers such as A. jolyana, we did not observe the expected differences on efficacy owed to differences on life-history and behavior between bees (see Westerkamp 1991). A previous study with another daisy, Heterotheca subaxillaris, conducted in meadows and grasslands in Central Texas, USA, also show similar efficacy of the most frequent visitors, and the overall relative effectiveness of pollinators is well represented by the visitation frequency of each pollinator (Olsen 1996).

There is much interest in comparing the efficacy and effectiveness of the honeybee to native pollinators 
in crop pollination (e.g. Freitas \& Paxton 1998; Vicens \& Bosch 2000) as well as in native plants (e.g. FumeroCabán \& Meléndez-Ackerman 2007; Hung et al. 2018). Such studies have shown that $A$. mellifera can be as good pollinator as native species in both crops and native plants (e.g. Freitas \& Paxton 1998; Rader et al. 2009; FumeroCabán \& Meléndez-Ackerman 2007; Hung et al. 2018). However, A. mellifera is sometimes less effective than native species in commercial crops (e.g. Vicens \& Bosch 2000) or even detrimental to the reproduction of the native flora in the invaded range (e.g. Gross \& Mackay 1998). Here, our data indicated that $A$. mellifera was equally effective in promoting seed set as the native bees. Moreover, when considering the visitation frequency, the honeybee is one of the most important pollinators, second only to the native bumblebee B. pauloensis. Nevertheless, the presence of other frequent and effective pollinators of $A$. jolyana suggests that eventual removal of this invasive species would not negatively impact this plant as native bees are able to provide reliable pollination services.

Despite the effective role of invasive $A$. mellifera as pollinator of the generalist $A$. jolyana, the effect of this abundant floral visitor on the niche breadth and population sizes of the native social bees from the campo rupestre is

A.

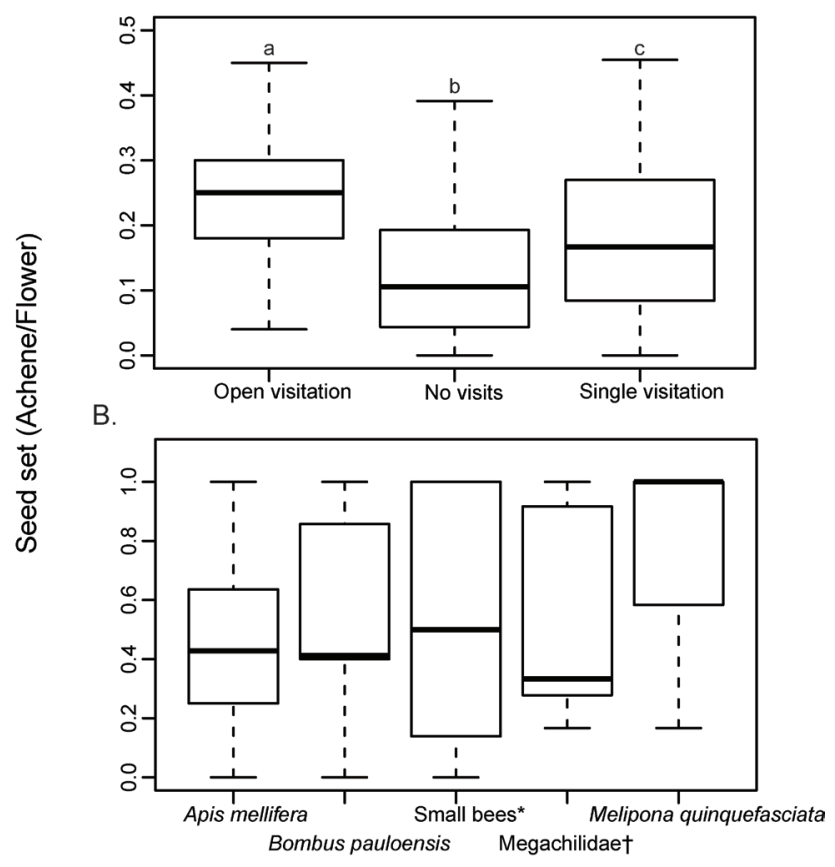

Figure 2. Seed set (conversion of florets to achenes) in Aspilia jolyana. A. Comparison of open visitation control (unrestricted visitation), no visits control (bagged) and single visitation capitula. Different letters denote statistically significant differences between categories (GLM, $\chi 2$ = 49.5, $\mathrm{P}<0.001$; post hoc Tukey $\mathrm{P}<0.01$ ). B. Comparison of pollination efficiency among the different bee species and groups showed no difference $(\chi 2=1.9, \mathrm{P}=0.75)$. See Table 1 for detail on the grouping of different bee species/ morphospecies (small bees* and Megachilidade bees $\dagger$ ). still largely unknown. The few studies performed in the Neotropical region show little or no impact of Africanized honeybee in the populations of both social and solitary native bees (Roubik 2009; Roubik \& Villanueva-Gutiérrez 2009). However, due to the scarce number of comprehensive studies, the literature does not allow any extensive generalization about the impact of $A$. mellifera introduction on the Neotropical bee fauna (Paini 2004).

In conclusion, we showed that frequent bee visitors, including several native species and the invasive honeybee, are equally good pollinators for a generalist daisy from the rupestrian grasslands. Aspilia jolyana showed high level of both ecological and functional generalization, conforming to its role as one of the species in the core of the local plantpollinator network (Carstensen et al. 2016). The ability of A. jolyana to rely on different pollinators indicates resilience of its populations to possible fluctuations in the pollinator fauna, as well as diversified mating opportunities with different pollinators providing distinct pollen dispersal. All these characteristics suggest generalization as an interesting reproductive strategy.

\section{Acknowledgements}

We thank Daniel W. Carstensen for initial guidance and for sharing data. We also thank several members of the Phenology Lab group, UNESP Rio Claro for the logistical support and assistance in the field; the Reserva Vellozia and private land owners. Funding was provided by CNPq (400717/2013-1), São Paulo Research Foundation (FAPESP grant \#2013/50155-0 to LPCM and grant \#2015/21457-4 to PKM) and by CAPES through a PNPD Postdoctoral grant to $C E P N$. LPCM receives a research productivity fellowship from CNPq.

\section{References}

Brito VL, Rech AR, Ollerton J, Sazima M. 2017. Nectar production, reproductive success and the evolution of generalised pollination within a specialised pollen-rewarding plant family: a case study using Miconia theizans. Plant Systematics and Evolution 303: 709-718.

Carstensen DW, Sabatino M, Morellato LPC. 2016. Modularity, pollination systems, and interaction turnover in plant-pollinator networks across space. Ecology 97: 1298-1306.

Carstensen DW, Sabatino M, Trøjelsgaard K, Morellato LPC. 2014. Beta diversity of plant-pollinator networks and the spatial turnover of pairwise interactions. PLOS ONE 9: e112903. doi: 10.1371/journal. pone.0112903

Dupont YL, Hansen DM, Valido A, Olesen JM. 2004. Impact of introduced honey bees on native pollination interactions of the endemic Echium wildpretii (Boraginaceae) on Tenerife, Canary Islands. Biological Conservation 118: 301-311.

Fenster CB, Armbruster WS, Wilson P, Dudash MR, Thomson JD. 2004. Pollination syndromes and floral specialization. Annual Review of Ecology, Evolution, and Systematics 35: 375-403.

Freitas BM, Paxton RJ. 1998. A comparison of two pollinators: the introduced honey bee Apis mellifera and an indigenous bee Centris tarsata on cashew Anacardium occidentale in its native range of $\mathrm{NE}$ Brazil. Journal of Applied Ecology 35: 109-121. 


\section{Are native bees and Apis mellifera equally efficient pollinators of the rupestrian grassland daisy Aspilia jolyana (Asteraceae)?}

Freitas L. 2013. Concepts of pollinator performance: is a simple approach necessary to achieve a standardized terminology? Brazilian Journal of Botany 36: 3-8.

Fumero-Cabán JJ, Meléndez-Ackerman EJ. 2007. Relative pollination effectiveness of floral visitors of Pitcairnia angustifolia (Bromeliaceae). American Journal of Botany 94: 419-424.

Gross CL, Mackay D. 1998. Honeybees reduce fitness in the pioneer shrub Melastoma affine (Melastomataceae). Biological Conservation 86: 169-178.

Hung KLJ, Kingston JM, Albrecht M, Holway DA, Kohn JR. 2018. The worldwide importance of honey bees as pollinators in natural habitats. Proceedings of the Royal Society, Biological Sciences 285: 20172140. doi: 10.1098/rspb.2017.2140

King C, Ballantyne G, Willmer PG. 2013. Why flower visitation is a poor proxy for pollination: measuring single-visit pollen deposition, with implications for pollination networks and conservation. Methods in Ecology and Evolution 4: 811-818.

Martín González AM, Dalsgaard B, Olesen JM. 2010. Centrality measures and the importance of generalist species in pollination networks. Ecological Complexity 7: 36-43.

Maruyama PK, Oliveira GM, Ferreira C, Dalsgaard B, Oliveira PE. 2013. Pollination syndromes ignored: importance of non-ornithophilous flowers to Neotropical savanna hummingbirds. Naturwissenschaften 100: 1061-1068.

Morellato LPC, Silveira FAO. 2018. Plant life on campo rupestre: new lessons from an ancient biodiversity hotspot. Flora 238: 1-10.

Mota GS, Luz GR, Mota NM, et al. 2018. Changes in species composition, vegetation structure, and life forms along an altitudinal gradient of rupestrian grasslands in south-eastern Brazil. Flora 238: 32-42.

Ollerton J, Killick A, Lamborn E, Watts S, Whiston M. 2007. Multiple meanings and modes: on the many ways to be a generalist flower. Taxon 56: 717-728.

Ollerton J, Rech AR, Waser NM, Price MV. 2015. Using the literature to test pollination syndromes-some methodological cautions. Journal of Pollination Ecology 16: 119-125.

Olsen KM. 1996. Pollination effectiveness and pollinator importance in a population of Heterotheca subaxillaris (Asteraceae). Oecologia 109: 114-121.
Paini DR. 2004. Impact of the introduced honey bee (Apis mellifera) (Hymenoptera: Apidae) on native bees: A review. Austral Ecology 29: 399-407.

R Core Team. 2016. R: A language and environment for statistical computing. Vienna, R Foundation for Statistical Computing.

Rader R, Howlett BG, Cunningham SA, et al. 2009. Alternative pollinator taxa are equally efficient but not as effective as the honeybee in a mass flowering crop. Journal of Applied Ecology 46: 1080-1087.

Rosas-Guerrero V, Aguilar R, Martén-Rodríguez S, et al. 2014. A quantitative review of pollination syndromes: do floral traits predict effective pollinators? Ecology Letters 17: 388-400.

Roubik DW. 2009. Ecological impact on native bees by the invasive Africanized honey bee. Acta Biológica Colombiana 14: 115-124.

Roubik DW, Villanueva-Gutiérrez R. 2009. Invasive Africanized honey bee impact on native solitary bees: A pollen resource and trap nest analysis. Biological Journal of the Linnean Society 98: 152-160

Silveira FA, Negreiros D, Barbosa NP, et al. 2016. Ecology and evolution of plant diversity in the endangered campo rupestre. Plant and Soil 403: 129-152.

Souza CS, Maruyama PK, Aoki C, et al. 2018. Temporal variation in plantpollinator networks from seasonal tropical environments: higher specialization when resources are scarce. Journal of Ecology doi. org/10.1111/1365-2745.12978

Thomson D. 2004. Competitive interactions between the invasive European honey bee and native bumble bees. Ecology 85: 458-470.

Vicens N, Bosch J. 2000. Pollinating efficacy of Osmia cornuta and Apis mellifera (Hymenoptera: Megachilidae, Apidae) on 'red Delicious' apple. Environmental Entomology 29: 235-240.

Waser NM, Chittka L, Price MV, Williams NM, Ollerton J. 1996. Generalization in pollination systems, and why it matters. Ecology 77: 1043-1060.

Westerkamp C. 1991. Honeybees are poor pollinators - why? Plant Systematics and Evolution 177: 71-75.

Zuur AF, Leno EN, Walker NJ, Saveliev AA, Smith GM. 2009. Mixed effects models and extensions in ecology with R. New York, Springer. 